\title{
Model Approaches for Simulation of Processes in Rod and Wire Production
}

\author{
Matthias Schmidtchen ${ }^{1, a *}$, Pavel Adamyanets ${ }^{2, \mathrm{~b}}$ and Rudolf Kawalla ${ }^{3, \mathrm{c}}$ \\ ${ }^{1-3}$ TU Bergakademie Freiberg, Institute of Metal Forming, Bernhard-von-Cotta-Str. 4, D-09596 \\ Freiberg, Germany \\ amatthias.schmidtchen@imf.tu-freiberg.de, bpavel.adamyanets@imf.tu-freiberg.de, \\ crudolf.kawalla@imf.tu-freiberg.de \\ * corresponding author
}

Keywords: simulation, rod rolling, groove pass design

\begin{abstract}
Actual improvements in rod or wire production e.g. in relation to power requirements, energy consumption and final material properties demand powerful simulation tools for process optimisation, pre-setting calculations or automation. The groove pass design model of TU Bergakademie Freiberg was developed and applied for those purposes. This paper provides a short overview of the history of the model approaches and highlights some important stages of development.
\end{abstract}

\section{Introduction}

Nowadays, the continuously intensified production is closely connected to the increasing rolling speed and the highest possible energy savings, which are both typical demands of modern rod and wire rolling mills. At the same time, increasing restrictions on the value and scatter of final mechanical properties and optimisation of the final shape, demand for the use of fast numerical simulation tools with increasing modelling depth. In calibre rolling, a three axial stress and strain state dominates in contradiction to flat rolling, arising from an interplay of free and disabled spread, due to rolling contact. This inhomogeneous deformation state will be reinforced in its influence on micro-structure evolution, development of residual stresses and in the end on mechanical properties of the work piece by an inhomogeneous temperature field. This is a result of an interplay between inhomogeneous plastic dissipation an locally varied thermal conditions. Due to this complexity of rod and wire rolling processes, numerical simulation is a fundamental element of a modern roll pass development or optimisation and groove design. To meet this requirements, an increasing computational speed with a simultaneously growing modelling depth is needed.

Currently, there are different approaches in use to solve those tasks. Initially, one-dimensional models for process design $[1,2,3,4,5]$ were quickly followed by computer approaches based on upper bound or finite element methods [6]. As an alternative, fast computational methods were developed, which can also be used for a simulation of local forming processes.

The following paper will give an overview of modelling approaches for a fast computation of rod and wire rolling processes developed at the Institute of Metal Forming of TU Bergakademie Freiberg, their opportunities and limitations.

\section{Model approaches for rod and wire rolling at TU Bergakademie Freiberg - a historical review}

Origin of all model developments are these explained requirements for a creation of a fast tool that ensures a groove pass design with an uniform utilization of rolling mills. In the beginning, typical design criteria were: temperature development $\vartheta$ along the rolling line, roll forces $F$, roll torque $M_{W}$, roll power $P$, energy consumption and intermediate or final shape. With the increase of strain rate $\dot{\varphi}$ and especially for steel grades growing importance of thermo-mechanical treatments (TMB), the temperature distribution within the work pieces, micro-structure evolution during the whole rolling process and the final properties stepped into the focus. These general tendencies are also reflected by the development of the Freiberg groove pass models. 

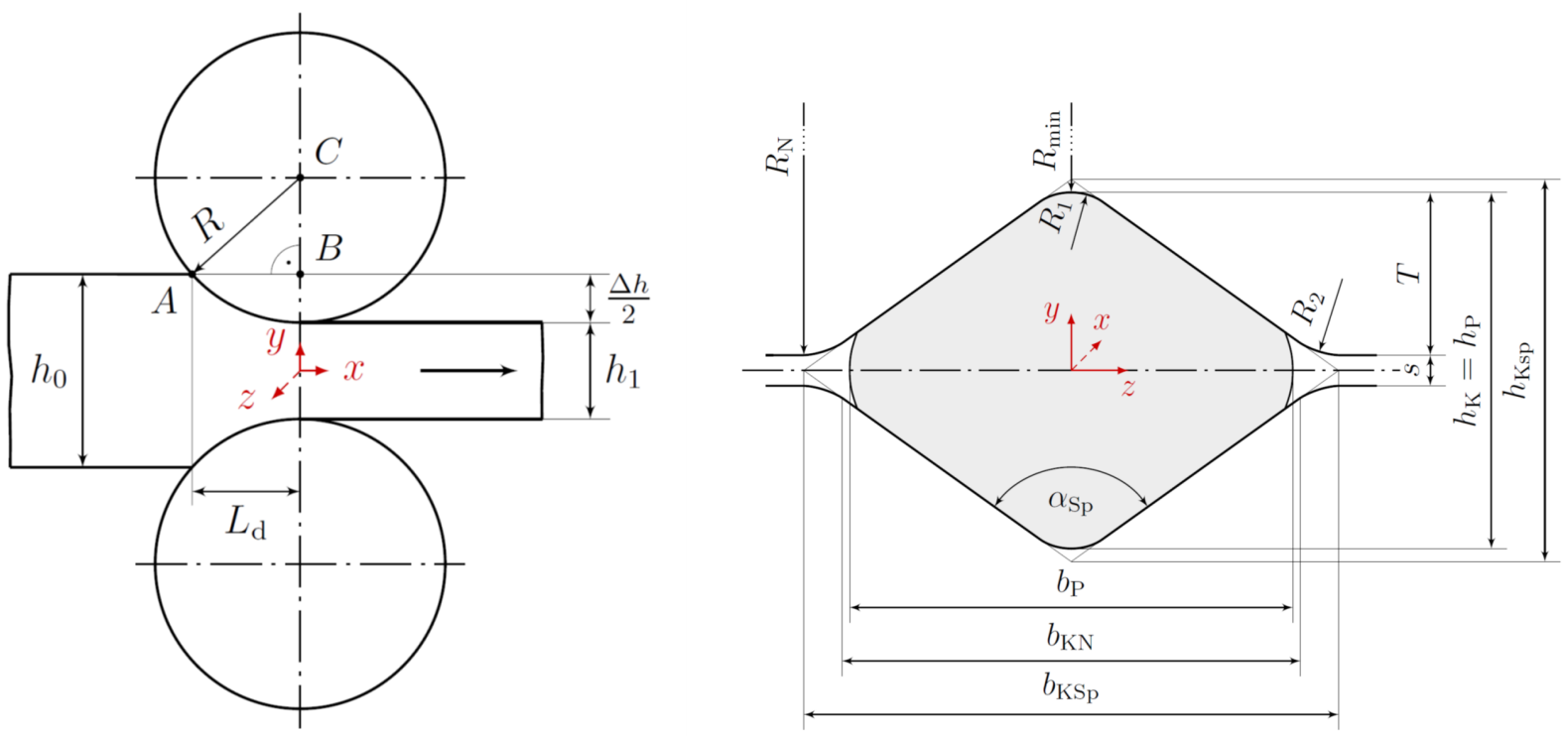

Figure 1: Coordinates and characteristic values in rolling

Correct predictions of contact area $A_{d}$, shape of deformation zone, groove filling or dimensional tolerance, are the basis of all further computations. On one hand, these entities are determined by the shape of grooves, on the other hand by spreading $\beta$ and elongation $\lambda$ of the material. Usually spread is predicted by the method of equivalent rectangle [3]. Therein, the equivalent rectangle has the same area of cross-section and the same maximum width as the true calibre. Spread will be calculated by suitable model for flat rolling, e.g. Wusatowski [1]. With the maximum width, the result is transferred back to the final shape of cross-section. Any other needed entity is being calculated from this equivalent, virtual flat rolling pass. Hensel and Spittel introduced an improved method in [3] were the thickness-towidth ratio is also taken into consideration. In addition, the maximum width is similar to the one the of cross-section. Nevertheless, experimental and theoretical investigations had shown large differences between theory and experimentally predicted spread, especially for increasing calibre diagonal ratio $a_{k s p}=b_{k s p} / h_{k}$ or underfilled grooves, Fig. 1 .

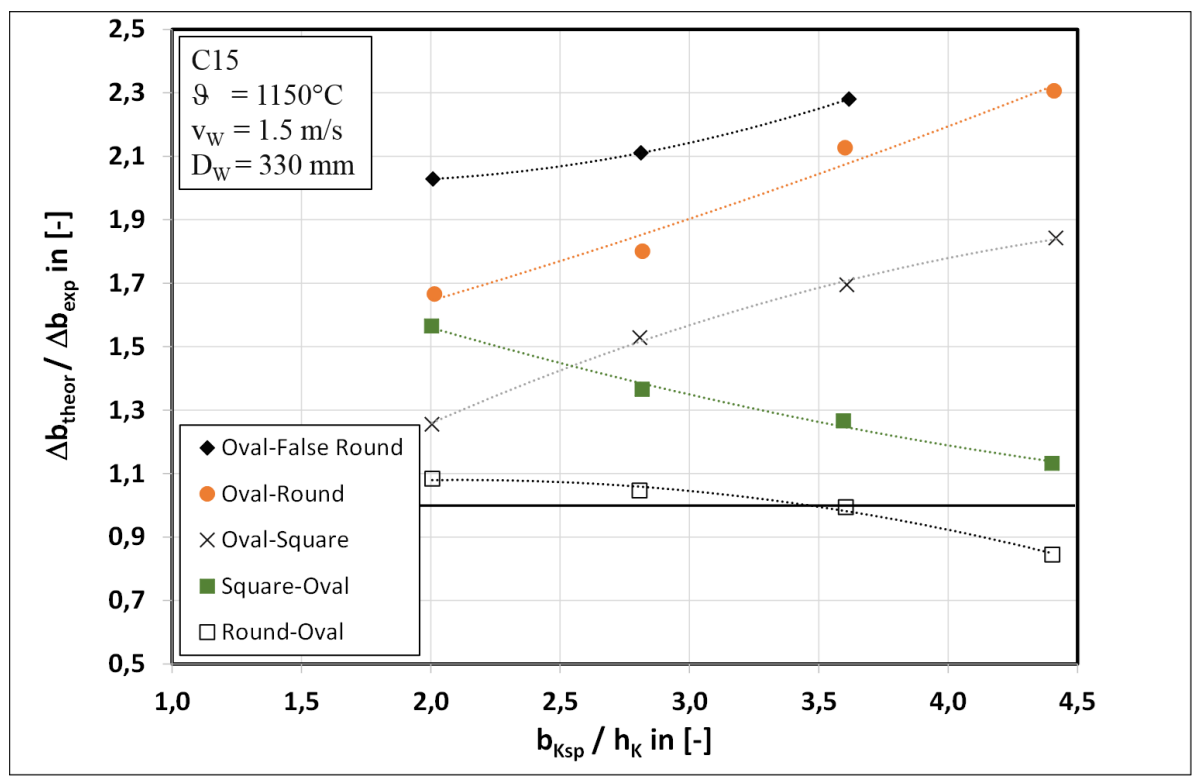

Figure 2: Deviations between spread predicted in experimental investigations by Kunzmann [7] and computations results from method of equivalent rectangle 
Some results from Kunzmann [7] are shown in Fig. 2. To enhance the accuracy of the calculations, the spread predicted by the equivalent rectangle method is usually being corrected by additional coefficients or functions, see e.g. [8]. Hensel and Kunzmann introduced instead a new method for direct computation of spreading, using the original size of cross section, roll gap ratio and other process parameter, Fig. 3, Table 1 and $[5,9,10]$. This model was developed, based on extensive experimental investigations, performed at the semi-continuous rolling mill of TU Bergakademie Freiberg and additional industrial trials. Due to the complex strain state, spreading and elongation are needed at the same time for a calculation of the maximum width of the final cross section and the pressed area $A_{d}$. The accuracy of the $A_{d}$ influences linearly the calculation of roll force and torque. The multiplicative approach of this model, Fig. 3, was derived from similarity considerations. Within further experimental analyses, empirical function reflecting the influence of material $C_{W}$, temperature dependence $C_{\vartheta}$, rolling speed $C_{v}$, friction $C_{\mu}$, roll gap ratio $C_{K}$, tension $C_{L}$, filling of groove $m$ and aspect ratio were developed $C_{G}$ or $C_{A} a_{K n}^{n}$. These experiments had highlighted a need of a further subdivision of the model for different kinds of roll pass sequences. The basic structure of the spreading model is given in Table 1. All material independent functions, written in Fig. 3 within the dashed box, were predicted based on trials using the steel grade $\mathrm{C} 15(1.0401)$ at $1000^{\circ} \mathrm{C}$. Material and temperature functions $C_{W}, C_{\theta}$ are used to correct the spreading behaviour for the material actually used and its specific temperature dependence. The central term in both models is the function representing the influence of aspect ratio, now defined with $a_{K n}=b_{K N} / h_{K}$. Here, the largest ratio for incoming or out going cross section is used. An detailed overview of all coefficients was given in $[5,11]$. Different kinds of sets are needed for spread and elongation.

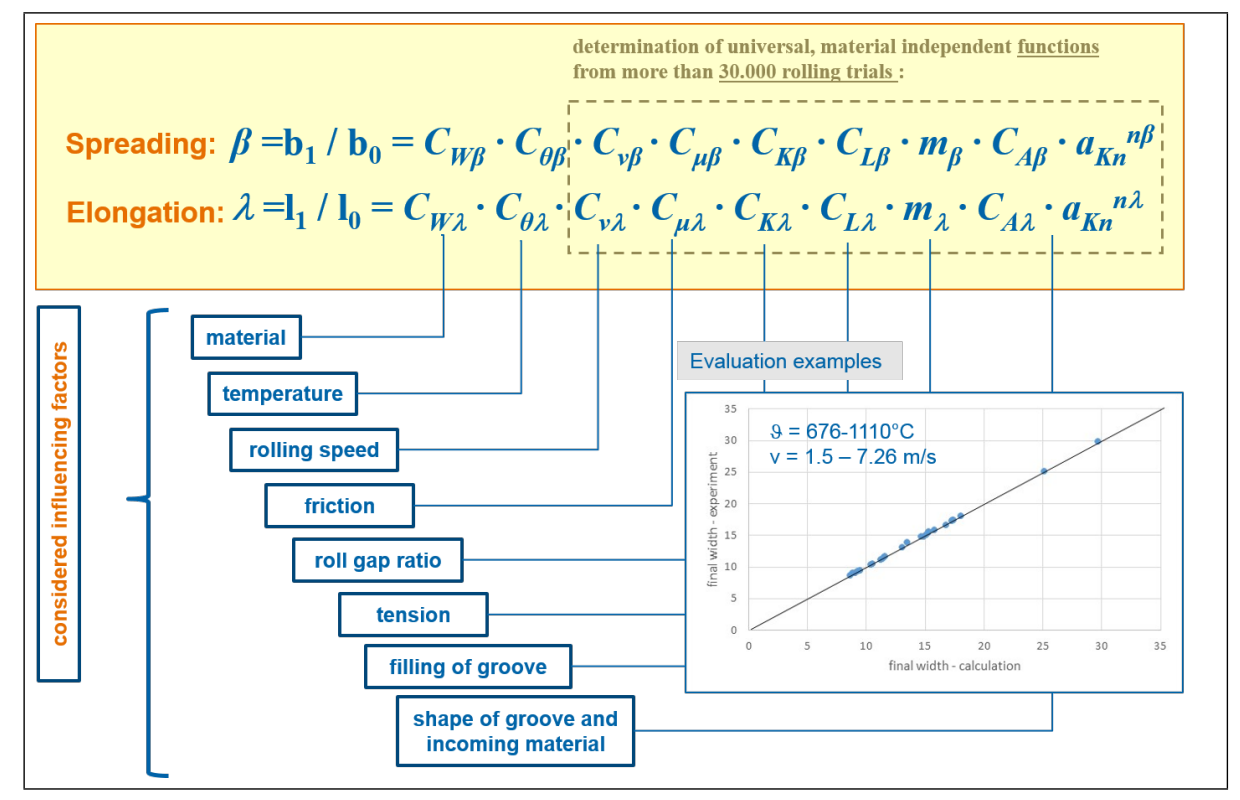

Figure 3: Meaning of the particular functions within the multiplicative model for spreading calculation after Hensel $[5,10]$

This data sets were developed for 16 break down pass sequences, more than 40 alloys and an optimum groove filling within the range of $i_{p}=b_{p} / b_{K N}=0.88 \ldots 0.96$. In actual investigations the opportunity of a further extension of the range of validity was tested, Fig. 4 . It was found, that a change within the meaning of the parmeters $i_{b}$ and $a_{K N}$ is needed to improve the accuracy of the model. For a groove filling below $i_{b}<i_{b l i m i t}$, the usual meaning of $i_{b}=b_{p} / b_{K N}$ and $a_{K N}=b_{K N} / h_{K}$ is used whereas in the range $i_{b} \geq i_{b l i m i t}$ the definition $i_{b}=b_{p 1} / b_{K s p}$ and $a_{K N}=b_{p 1} / h_{K}$ is applied, see Fig. 4. As it is shown the range of validity is extended up to $i_{b} \leq 1.20$ with an error below $5 \%$. Using $b_{K s p}$ instead of $b_{K N}$ the maximum error can be further reduced for this kind of pass- sequences. 


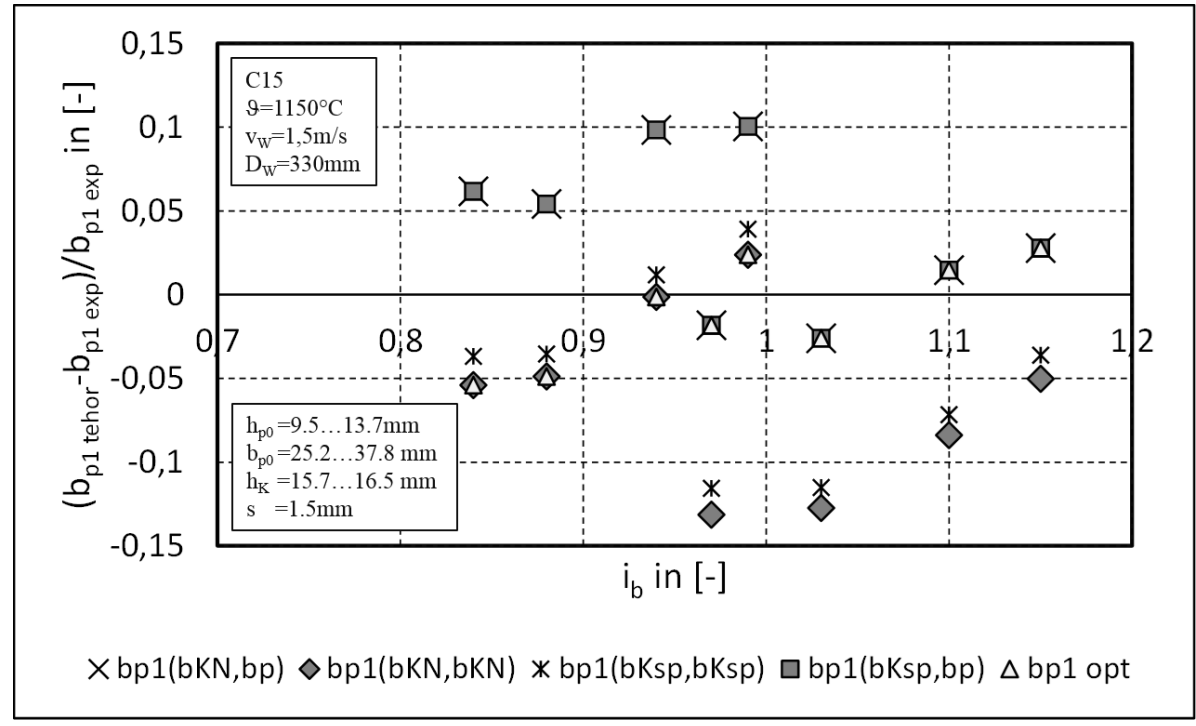

Figure 4: Deviations between spread predicted in experimental investigations of a oval-round pass by Kunzmann [7] for different groove filling $i_{b}=b_{p 1 \text { exp }} / b_{K N \text { oval }}$ and computational results using the Freiberg model after Tab. 1 with different approaches for the calculation of groove filling $i_{b}$ and calibre-diagonal-ratio $a_{K}$

For further calculations, the knowledge of final cross-section $A_{p 1}$ and pressed area $A_{d}=L_{d} B_{m}$ is needed. The shape of final cross-section within the area of tool contact $|x| \leq x_{c}$ is given by the contour of the groove, whereas the area of cross-section is easily predicted from the elongation function $\lambda=A_{p 0} / A_{p 1}$ shown in Fig. 3 as well.

In the range of free spreading $|x|>x_{c}$, a contour of the free boundary needs to be assumed. By means of the calculated final width $b_{p 1}$ and $A_{p 1}$ a circular arc or parabola is fitted. The prediction of pressed area demands the knowledge of the shape of deformation zone. Based on comprehensive experimental investigations, Zhouhar developed empirical equations, Eq. 1, for this entity for several pass sequences (round-oval, oval-round, square-diamond, diamond-square, diamond-diamond and square-oval, oval-square), [5, 12]. This formulas were modified, after actual experimental investigations, by the means of modern optical measurement methods by Adamyanets [13] (round-oval, oval round) and Helbig [14] (square-diamond, diamond square).

$$
\begin{aligned}
& A_{d}=K\left\{b_{1} y L_{d}+\frac{1}{2} L_{d}\left(x b_{0}+b_{1}\right)(1-y)\right\} . \\
& L_{d}=\sqrt{R_{\min }\left(h_{K 0}-h_{K 1}\right)} .
\end{aligned}
$$

Eq. 1 was developed for optimum groove filling, similar to the original spreading model. $\mathrm{H}$. Wehage and J. Wehage introduced a bar model to improve the flexibility of the geometrical model and to make locally information on strain and strain rate available. The initial cross-section is subdivided into equidistant bars that will be deformed individually, without bulging. A homogeneous distribution of the strain along the $z$-axis perpendicular to the rolling direction were assumed first [11]. Improved results were obtained by B. Schmidt [15] using a linear distribution along $z$.

A different approach was developed by Krause [16, 17]. Within the DFG priority program SPP1204 "Algorithms for fast, material specific process chain design and analysis in metal forming" a numerical model for the evolution of a mean logarithmic strain $\varphi_{l}(x)=\varphi_{l 1}\left(1-\cos \left[\pi x / L_{d}\right]\right) / 2$ in longitudinal direction with $\varphi_{l 1}=\ln \left[\lambda_{1}\right]$ and a strain distribution within the deformation zone was developed, based on a Finite Element (FEM) parameter study. In analogy to the calculation of the shape of the final cross-section any intermediate section and thus the whole shape of the deformation zone, can be predicted in connection with the contour of the groove. The Contour and pressed area itself will follow 
Table 1: Description of particular functions within the spreading model after Hensel [10] and coefficients for the roll pass oval- round used in Fig. 4

\section{Function Formula}

material faktor $\quad C_{W}=$ const.

thermal function $C_{\vartheta}(\vartheta)=\left\{\begin{array}{l}a e^{(b \vartheta)}+c \\ a+b \vartheta\end{array}\right.$

rolling speed $\quad C_{v}(v)=\left\{\begin{array}{l}1-d_{2}(v-1.5) \text { with } v \text { in } \mathrm{m} / \mathrm{s} \\ d_{6}\left(v-v_{\text {min }}\right)^{d_{7}}+d_{8}\end{array}\right.$

friction faktor $\quad C_{\mu}$

roll gap ratio $\quad K\left(\frac{R}{h_{1}}\right)^{n}$

tension function $\quad C_{L}=1-n_{L} \frac{v_{z}-v_{n z}}{v_{n z}}$

$v_{z}-v_{n z} \ldots$ velocity difference between stands

$v_{n z} \ldots$ velocity without tension

filling function $\quad m_{\beta}\left\{\begin{array}{l}a_{1} i_{b}^{c_{1}}+b_{1} \text { if } i_{b} \leq i_{b l i m i t} \\ a_{2} i_{b}^{c_{2}}+b_{2} \text { if } i_{b}>i_{\text {blimit }}\end{array}\right.$

with $i_{b}=b_{p} / b_{K N}$

and $i_{\text {blimit }}$ upper limit for optimum filling of a specific calibre

shape function $\quad C_{G}=C_{A} a_{K N}^{n_{G}}$

$$
\begin{array}{ll} 
& C_{W}=1, a=-0.000010838, b=0.007537, c=1.02, \\
\text { coefficients for } & C_{m u}=1.095, d_{2}=0.001, d_{6}=0.016, d_{7}=-0.35, d_{8}=0.986, \\
\text { oval-round pass } & v_{\text {min }}=0.01, K=0.8317, n=0.08, n z u g=0, i_{b l i m i t}=0.98, \\
& a_{1}=0.13498, b_{1}=0.901, c_{1}=11.5, C_{A}=1.03, n_{G}=0.28
\end{array}
$$

directly from this solution. Assuming a quadratic distribution of the logarithmic strain $\varphi_{h}$ along the $y$-direction, using the symmetries of the break down passes, a distribution of the logarithmic strain $\varphi_{h}(x, y, z)$ can be predicted. By means of the mass balance, the local equivalent logarithmic strain is given. Strain rate distributions will be predicted in a similar way. In analogy to the method of equivalent rectangle this equivalent value is predicted from the deformation of the equivalent system $\varphi_{V}=$ $2 \sqrt{\varphi_{h m}^{2}+\varphi_{l m}^{2}+\varphi_{h m} \varphi_{l m}} / \sqrt{3}$ as a mean value, [18]. This causes larger deviation in comparison to experiments.

Spread is effectively controlled in continuous mills by tension arising from differences in rolling speed. A precise pre-setting or roll pass schedule development with tension needs the knowledge of backward slip $s_{0}=1-v_{0} /\left(v_{w m} \cos \alpha_{0}\right)$ and forward slip $s_{1}=\left(v_{1} / v_{W m}\right)-1$ with $v_{W m}$ as the 
mean circumferential speed within the groove. These entities were also experimentally predicted in addition to the spreading behaviour, [19, 20,21]. With the use of mass flux balance and the shape of the deformation zone $A_{p}(x)$, the mean velocity of the work piece can be predicted. Calculating backwards from $s_{1}$, the exit of the roll gap or the position of the mean neutral line $x_{F l}$ is given by $v\left[x_{F l}\right]=v_{W m}$. In other cases, an estimation of the position of neutral line is made by $\sin \alpha_{F l}=$ $\sin \alpha_{0 m} / 2-\left(1-\cos \alpha_{0 m}\right) / 2 \mu$. Here $\alpha_{0 m}$ is the mean bite angle and $\mu$ the friction coefficient. This equation is predicted from force balance along the whole contact area between the calibre and the deformed material, assuming Coulomb friction and constant pressure. Other approaches using the calculation of the flat rolling pass in the method of equivalent rectangle.

The development of a mean temperature throughout the rolling process was initially predicted by a $1 \mathrm{D}$ heat flux balance, neglecting conduction in direction of rolling $[5,10]$. With the application of the bar model, the opportunity for a prediction of local temperatures was given. Heat exchange between the bars was excluded in the work of e.g. Wehage [11] or Blinov [22]. Nevertheless, this methods were accurate enough to calculate the influence of thermal differences between the surface and the core. Nowadays, methods as Finite Differences or FEM are being used $[6,16]$.

At the beginning of roll pass simulation, a flow stress model as it was developed by Hensel and Spittel, Eq. 3, as well as thermo-physical data were sufficient $[3,4,5,23]$. With increasing importance of thermo-mechanical treatment for steel rod and wire production, models for softening kinetics were include more and more. To ensure the high speed of computation, up until now, softening kinetics based on the approach of Johnson-Mehl-Avrami-Kolmogorov (JMAK) were mainly used [16, 24, 25]. By means of the local material flow models of e.g. Krause, a detailed computation of locally different phase-transformation and with that the final mechanical properties of the material where possible. These models are based on experimentally predicted deformation-time-temperature diagrams and their approximation as well as on empirical equations for yield and ultimate stress given e.g. by [24, 25].

$$
\sigma_{F m}=A e^{m_{1} \vartheta} \varphi_{V}^{m_{2}} \dot{\varphi}_{V}^{\left(m_{3}+m_{8}\right) \vartheta}\left(1+\varphi_{V}\right)^{\left(m_{5} \vartheta+m_{6}\right)} e^{m_{7} \varphi_{V}} e^{\frac{m_{4}}{\varphi_{V}}} \vartheta^{m_{9}} .
$$

Roll force, torque, power and energy consumption where initially predicted after Siebel and Lueg [26] by means of the method of equivalent rectangle and slab theory. With growing experimental base, this method was substituted by semi-empirical equations. Therefore, the general equation for deformation forces in processes with direct acting pressure where rewritten as $F=\sigma_{F m} A_{d}\left[K_{W m} / \sigma_{F m}\right]$. The relative forming resistance $K_{W m} / \sigma_{F m}$ represents the reciprocal value of the efficiency of the process and can be approximated after e.g. $[5,10,11,15]$, by means of the semi-empirical equation, Eq. 4. From similarity considerations it is known that $K_{W m} / \sigma_{F m}$ mainly depends on roll gap ratio $A_{d} / A_{m}$, but also on relative friction $\tau_{R} / \sigma_{F m}$, strain $\varepsilon_{h}$ and initial aspect ratio $h_{p 0} / b_{p 0}$. Hensel [5] published an approximation of the mean function for mean values whereas Schmidt [15] published individual equations for rolling of blooms, slabs, billets as well as different break down pass sequences.

$$
\frac{k_{W m}}{\sigma_{F m}}=k_{1}+k_{2} \frac{A_{d}}{A_{m}}+k_{3}\left(\frac{A_{d}}{A_{m}}\right)^{2}+k_{4} \exp \left[-k_{5} \frac{A_{d}}{A_{m}}\right]+k_{6} \exp \left[-k_{7}\left(\frac{A_{d}}{A_{m}}\right)^{2}\right] \text {. }
$$


The total rolling torque will be calculated using the general equation $M_{W}=2 F m L_{d}$, with $0<$ $m<1$ as the lever arm coefficient. For this coefficient, a similar equation as for the relative forming resistance, can be found, Eq. 5. It also depends on the geometry, on rolling speed and temperature. Hensel et.al [5] published separate equations for roughing mill and finishing train to improve the accuracy of calculations.

$$
m=\frac{a_{M}}{L_{d}}=\left(\exp \left[-a \frac{A_{d}}{A_{m}}\right]+b \frac{A_{d}}{A_{m}}\right) v_{W}^{c} \exp \left[-d\left(\vartheta-\vartheta_{\text {base }}\right)\right] .
$$

Rolling power $P=M_{W} \omega$ follows directly from rolling torque and angular speed $\omega$ and motor power from $P_{M}=P /\left(\eta_{L} \eta_{K W} \eta_{g} \eta_{M}\right)$ where $\eta_{L} \eta_{K W} \eta_{g} \eta_{M}$ are the coefficients of efficiency.

\section{Application to Magnesium alloys and different roll pass sequences}

In the last decade, a steadily growing interest on rod rolling of light metals especially aluminium and magnesium alloys were observed. To meet the requirements of a proper groove pass design or roll pass simulation the Freiberg groove pass model was also extended to magnesium alloys AZ31, AZ81, WE43. First results were reported e.g. in [27].

Table 2: Coefficients $C_{W}$ and $C_{\vartheta}=a+b \vartheta$ for application of the Freiberg spreading model to Magnesium alloys

\begin{tabular}{lcccc} 
Material & $C_{W}$ & $\boldsymbol{a}$ & $\boldsymbol{b}$ & $\vartheta_{\text {base }}$ \\
& & & & \\
\hline AZ31 & 1.0541 & 0.848512 & $5.13331 \mathrm{E}-04$ & $300^{\circ} \mathrm{C}$ \\
AZ81 & 1.0020 & 0.8695 & $4.28 \mathrm{E}-04$ & $300^{\circ} \mathrm{C}$ \\
$\mathbf{W E 4 3}$ & 0.9119 & 0.886358 & $2.1962 \mathrm{E}-04$ & $480^{\circ} \mathrm{C}$
\end{tabular}

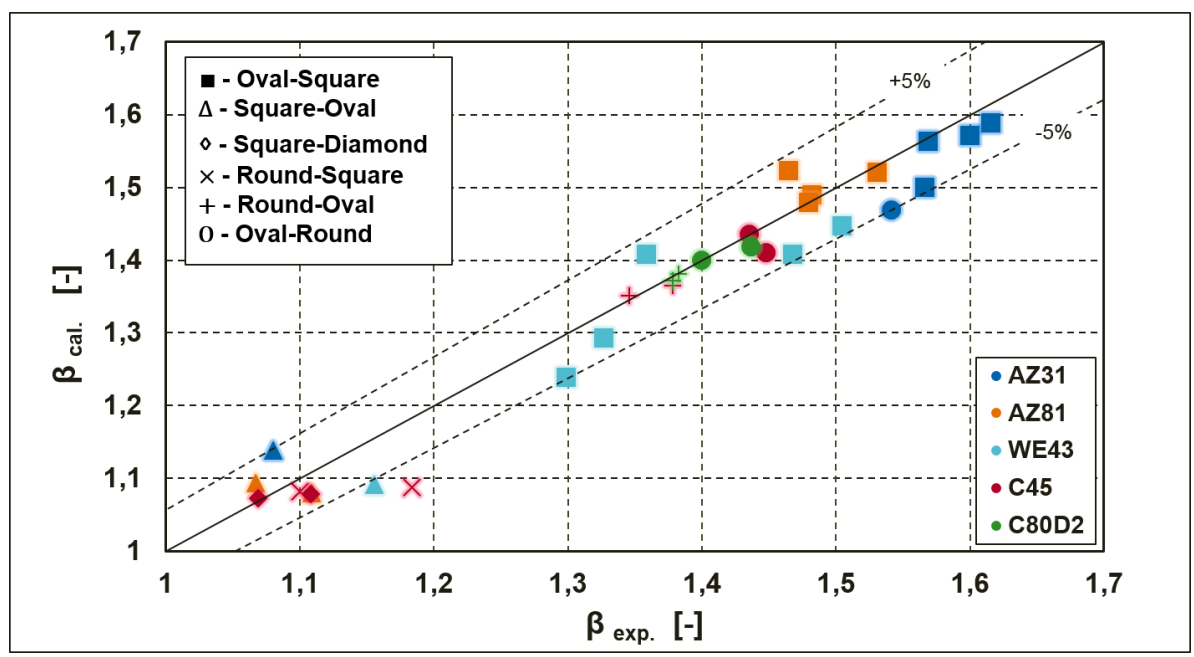

Figure 5: Application of spreading model Fig. 3 to ferrous and non-ferrous alloys at different groove sequences

Rolling trials on an open three-high train of TU Bergakademie Freiberg were used to predict material coefficient $C_{W}$, and thermal function $C_{\vartheta}$. Similar to the approach for steel grades, a reference temperature $\vartheta_{\text {base }}$ was defined, where $C_{\vartheta}\left(\vartheta_{\text {base }}\right)=1$. This temperature is different for each magnesium alloy and depends on the typical hot rolling temperature. For AZ-alloys it is set to $\vartheta_{\text {base }}=300^{\circ} \mathrm{C}$ 
(AZ31, AZ81) and $\vartheta_{\text {ref }}=480^{\circ} \mathrm{C}$ for WE-alloys (WE43). All coefficients are shown in Table 2. With these data, material flow, roll force and torque were calculated for several groove pass sequences. Comparisons between spread calculations for steel grades C45, C80D2 and magnesium alloys are given in Fig. 5 in relation to experimental predictions. For all materials a scatter of the relative errors in-between a range of $\pm 5 \%$ was obtained. Due the currently existing small numbers of rolling data for WE43 the temperature function needs to be improved. A comparison between experimental and theoretical data for rolling force and torque was given in [27]. A good agreement for AZ alloys were found. WE43 gives again the largest deviation between experiment and simulation in relation to the other Magnesium alloys. In general a greater spreading behaviour of the Mg-alloys AZ31 is obtained than it is known from rod rolling of steel grades. With increasing alloying content (AZ81 or WE43) spreading is significantly reduced, Fig. 6.

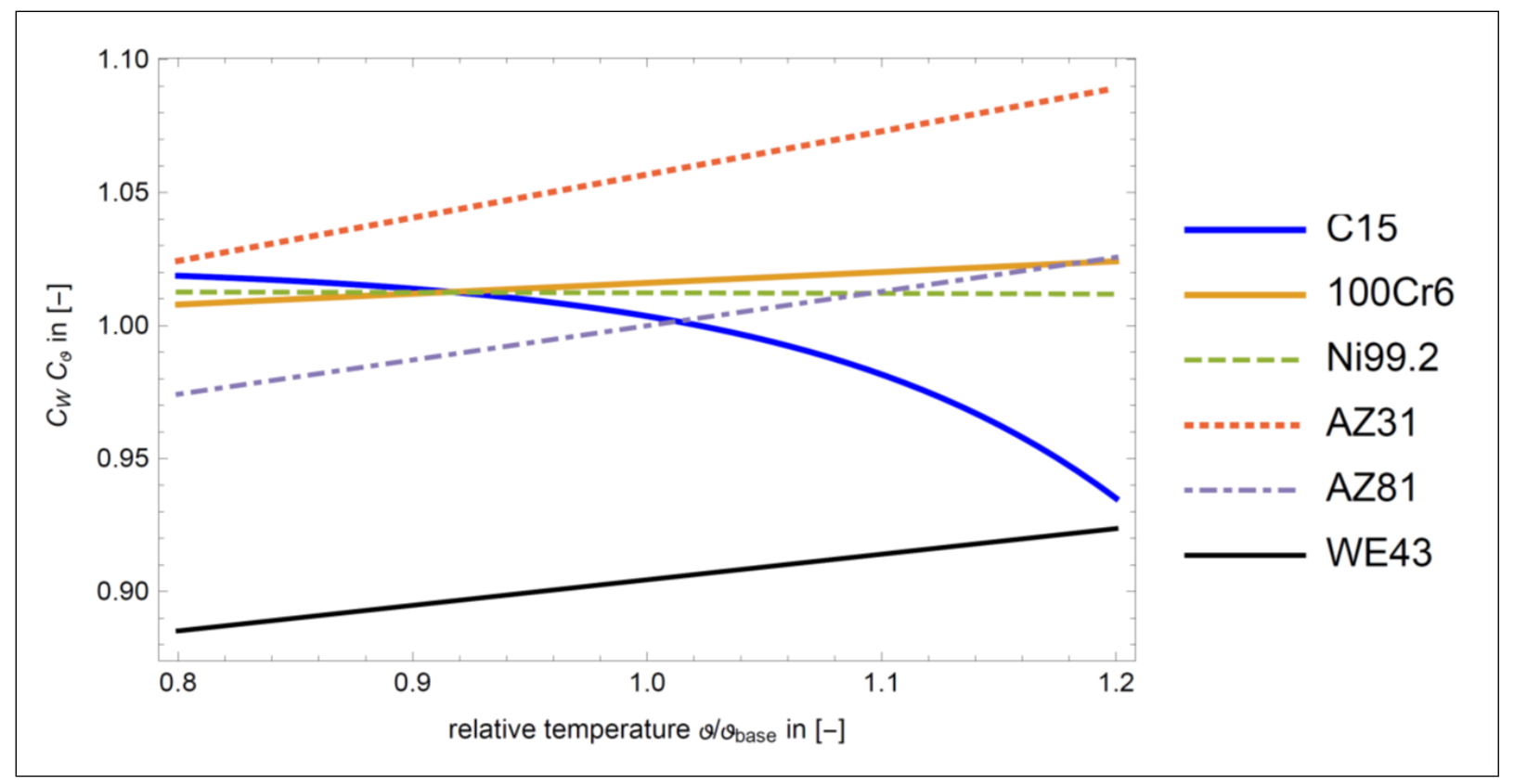

Figure 6: Comparison of temperature dependence of spreading between selected metals and magnesium alloys

\section{Summary and future work}

In the present paper, an overview of developments in groove pass simulation at the Institute for Metal Forming was given. Founded on a huge data base of experimental investigation a fast and precise model for material flow, roll force, torque and energy consumption has been developed. Modern technological tendencies have a great influence on the further model development. Although, there is an increasing modelling depth within the approach, it is still applicable for a fast computation for presetting or automation. Future work will focus on a more flexible approach for predictions of local spread and strain / strain rate distributions. New groove pass sequences and materials will be included in the data base in the future as well.

\section{Aknowledgement}

The authors will give their thanks to the German Research Foundation (DFG) for financial support of the development of particular models for rod and wire rolling within the priority program SPP 1204 "Algorithms for fast, material specific process chain design and analysis in metal forming". Special thanks will be given to Prof.(em.) Dr. sc. techn. Arno Hensel for the rewarding discussion concerning the "Freiberg groove pass model" and its industrial applications, his help and advice. 


\section{References}

[1] Z. Wusatowski, Grundlagen des Walzens, VEB Deutscher Verlag für Grundstoffindustrie, Leipzig, 1963.

[2] H. Neumann, Kalibrieren von Walzen, VEB Deutscher Verlag für Grundstoffindustrie, Leipzig, 1975.

[3] A. Hensel, T. Spittel, Kraft- und Arbeitsbedarf bildsamer Formgebungsverfahren, VEB Deutscher Verlag für Grundstoffindustrie, Leipzig, 1978.

[4] T. Spittel, A. Hensel, Efficient use of energy in forming processes (german: Rationeller Energieeinsatz bei Umformprozessen), VEB Deutscher Verlag für Grundstoffindustrie, Leipzig, 1983.

[5] A. Hensel, P. I. Poluchin, W. P. Poluchin (eds.), Technology of Metal Forming (german: Technologie der Metallformung), Deutscher Verlag für Grundstoffindustrie, Leipzig, 1990.

[6] J.G. Lenard, M. Pietrzyk, L. Cser, Mathematical and physical simulation of the properties of hot rolled products, Elsevier, Amsterdam, 1999.

[7] E. Kunzmann, Verfahrensoptimierung, gezeigt am Beispiel des Streckkaliberwalzens, Dissertation B, TU Bergakademie Freiberg, 1977.

[8] W. Smirnow, W. Schilow, Deformation and forces in grooves of simple shape, Deformatsii i usilya v kalibrah prostoi formy, Metallurgija, Moscow, 1982.

[9] A. Hensel, E. Kunzmann, Ausgewählte Beispiele beim Walzen in Streckkaliberreihen, Neue Hütte 23 (1978) No. 7 245-251.

[10] A. Hensel, Ein neues Rechenverfahren für das Walzen von Feinstahl und Draht, Neue Hütte 32 (1987) No. 5 183-189.

[11] H. Wehage, Beitrag zur rechnergestützten Erarbeitung von Projekten und Technologien für kontinuierliche Feinstahl- und Drahtstraßen, Ph.D. thesis, TU Bergakademie Freiberg, 1990.

[12] G. Zouhar, Umformungskräfte beim Walzen in Streckkaliberreihen, Ph.D. thesis, TU Bergakademie Freiberg, Freiberger Forschungshefte series B 52, 1960.

[13] P. Adamyanets, Erarbeitung einer Softwarelösung zur Berechnung von Streckkalibrierungen auf Basis des Computeralgebra-Systems Mathematica, Diploma thesis TU Bergakademie Freiberg, 2013.

[14] M. Helbig, Experimentelle und theoretische Untersuchungen zum Walzen in Streckkalibern mit Kaliberfolgen Raute-Quadrat und Quadrat-Raute, Diploma thesis TU Bergakademie Freiberg, 2015.

[15] B. Schmidt, Entwicklung und Erprobung einer Softwarelösung für die mathematische Simulation des Walzens von Langprodukten, Ph.D thesis TU Bergakademie Freiberg, Freiberger Forschungshefte series B 282, 1997.

[16] G. Krause, R. Kawalla, Simulation of Material Flow, Microstructure and Properties Evolution in Bar and Wire Rolling, steel research 78 (2007) No. 10/11 745-750.

[17] R. Kawalla, G. Krause, C. Kaufmann, Development of a simulation software for the analysis of multi-stage hot rolling processes of strip and rod/wire, steel research int. 79 (2008) No. 3 1-11. 
[18] H. Hoffmann, R. Neugebauer, G. Spur, Handbuch Umformen, second ed., Hanser, Munich, 2012.

[19] A. Hensel, G. Goldhahn, Untersuchung des Werkstoffflusses beim Walzen in der Streckkaliberreihe Rund-Oval, Neue Hütte 26 (1981) No. 2 51-55.

[20] A.Hensel, F. Gehre, Formänderungsverteilung sowie Kraft- und Arbeitsbedarf beim Walzen in Streckkalibern bei höheren Umformgeschwindigkeiten, Neue Hütte 30 (1985) No. 1 12-18.

[21] A. Hensel, L. Grossmann, Untersuchung des Stoffflusses in der Streckkaliberreihe Quadrat-Oval, Neue Hütte 32 (1987) No. 11 410-412.

[22] V. Blinov, Modellierung des Stoffflusses, der Gefüge- und Eigenschaftsentwicklung beim Warmwalzen von Flachprofilen aus Draht ausgewählter Stahlgüten, Ph.D. thesis TU Bergakademie Freiberg, 2004.

[23] T. Spittel, M. Spittel, Landolt-Börnstein, Group VIII Advanced Materials and Technologies Volume 2C, Part 1- Metal Forming Data of Ferrous Alloys, 2009, Part 2- Metal Forming Data of Lightweight Alloys, 2011, Part 3- Metal Forming Data of Heavy Metals, 2011.

[24] N. D. Coung, Mathematische Modellierung und Simulation der Gefügebildungsvorgänge beim Warmwalzen in Kalibern, Vorzugsweise beim Walzen von Stabstahl und Draht, Ph.D. thesis TU Bergakademie Freiberg, 1991.

[25] W. Lehnert, N. D. Coung, Integrated Model for Calculating Parameters of Steel during Rolling Microstructural and Forming in Continuous Mills, ISIJ international, 35 (1995) No. 9 1100-1108.

[26] E. Siebel, W. Lueg, Über den Formänderungswiderstand beim Walzen von Stahl in Kalibern, Mitt. K.-W.-Inst. Eisenforschung, 16 (1934) 105-112.

[27] P. Adamyanets, M. Schmidtchen, R. Kawalla, Extension of the Freiberger Model of Spread for the Calculation of Material Flow During Rolling of Long Products to a New Material Group of Mg alloys AZ31, AZ81, WE43, Key Engineering Materials, 716 (2016) 677-684. 